\title{
Composition, content and antioxidative activity of the carotenoids in yellow-fleshed sweetpotato (Ipomoea batatas L.)
}

\author{
Koji Ishiguro*1,4), Masaru Yoshinaga'), Yumi Kai'), Takashi Maoka ${ }^{3)}$ and Makoto Yoshimoto ${ }^{1,5)}$ \\ 1) Crop Functionality and Utilization Research Team, National Agricultural Research Center for Kyushu Okinawa Region, 6651-2 \\ Yokoichi, Miyakonojo, Miyazaki 885-0091, Japan \\ 2) Sweetpotato Breeding Research Team, National Agricultural Research Center for Kyushu Okinawa Region, 6651-2 Yokoichi, \\ Miyakonojo, Miyazaki 885-0091, Japan. \\ 3) Research Institute for Production Development, 15 Shimogamo-morimoto, Sakyo, Kyoto 606-0805, Japan \\ 4) Crop Functionality and Utilization Research Subteam (Hokkaido Region), National Agricultural Research Center for Hokkaido \\ Region, 9-4 Shinsei Minami, Memuro, Kasai, Hokkaido 082-0081, Japan \\ 5) Department of Domestic Science, Kagoshima Women's Junior College, 6-9 Korai, Kagoshima 890-8565, Japan
}

The total carotenoid contents in eight sweetpotato (Ipomoea batatas L.) cultivars or breeding lines with yellow flesh were evaluated by absorption spectrophotometry and compared to those of four cultivars with orange flesh. The content ranged from $1.3 \mathrm{mg} / 100 \mathrm{~g}$ dry weight to $3.9 \mathrm{mg} / 100 \mathrm{~g}$ dry weight in yellow-fleshed cultivars and from $13.5 \mathrm{mg} / 100 \mathrm{~g}$ dry weight to $39.9 \mathrm{mg} / 100 \mathrm{~g}$ dry weight in orange-fleshed cultivars. Seventeen carotenoids were detected in yellow- and orange-fleshed sweetpotato by HPLC analysis. The amount of carotenoids analyzed by HPLC correlated highly with the carotenoid content analyzed spectrophotometrically. The main carotenoids were $\beta$-carotene 5,8;5',8'-diepoxide (ca. $32 \%-51 \%$ ) and $\beta$-cryptoxanthin 5,8-epoxide (ca. 11\%-30\%) in yellow-fleshed cultivars/lines, while $\beta$-carotene (ca. 80\%-92\%) was dominant in orange-fleshed cultivars. These results suggest that the content of each carotenoid differs according to flesh color, yellow or orange, although the carotenoid component in the yellow and orange flesh was almost identical. The antioxidative activities of carotenoids isolated from yellow-fleshed sweetpotato were analyzed by the 2,2'-azino-bis (3-ethylbenzothiazoline-6-sulfonic acid) diammonium salt (ABTS) radical-scavenging activity. The activity of ipomoeaxanthin A was comparable to $\beta$-carotene, and that of $\beta$-cryptoxanthin 5,8 epoxide was the lowest. The carotenoids in yellow-fleshed sweetpotato might contribute to the prevention of some diseases due to their antioxidative effect. $\beta$-carotene epoxides and $\beta$-crypthoxanthin epoxides, which are abundant in the yellow-fleshed cultivars, are noteworthy components for the breeding selection of sweetpotato with deep yellow flesh.

Key Words: yellow-fleshed sweetpotato, $\beta$-cryptoxanthin epoxide, $\beta$-carotene epoxide, antioxidative activity, orange-fleshed sweetpotato.

\section{Introduction}

Sweetpotato (Ipomoea batatas L.) varieties with purple, orange and yellow flesh have been recently developed (Komaki and Yamakawa 2006). For example, cv. Ayamurasaki (Yamakawa 1998), Murasakimasari (Kashimura et al. 2005), Purple Sweet Load (Tamiya et al. 2003) and Akemurasaki (Sakai et al. 2010) with purple flesh, Sunny-Red (Yamakawa et al. 1999), J-Red (Yamakawa et al. 1997), Hamakomachi (Yoshinaga et al. 2006) and Ayakomachi (Kai et al. 2004) with orange flesh, and Tamaotome (Ishiguro et al. 2004a), Benimasari (Ishiguro et al. 2004b), Beniharuka (Kai et al.

Communicated by M. Iwanaga

Received June 28, 2010. Accepted August 20, 2010.

*Corresponding author (e-mail: kuro@affrc.go.jp)
2010) and Himeayaka with yellow flesh have been released. The main pigments are anthocyanin and $\beta$-carotene in the varieties with purple and orange flesh, respectively. Many commercial products, such as chips, cakes, juices and vinegar, have been developed using purple and orange cultivars (Komaki and Yamakawa 2006). The next breeding objective is to develop a cultivar with deep yellow flesh. Reports of the carotenoid composition of yellow-fleshed cultivars are scarce, although such cultivars are produced in large amounts in Japan.

A number of physiological functions are attributed to carotenoids. They include antioxidation and anticancer activities and protection against coronary heart disease and eye diseases, such as age-related macular degeneration and cataract (Mayne 1996). Antioxidation is an important characteristic of carotenoids. Yellow-fleshed sweetpotatoes have 
some carotenoids in their tubers; however, their antioxidative activities, other than those associated with $\beta$-carotene, have not been analyzed.

For this study, we analyzed the total content and composition of carotenoids in yellow-fleshed cultivars and breeding lines and compared them to those of orange-fleshed cultivars. The antioxidative effect of carotenoids isolated from yellow-fleshed tubers was also evaluated.

\section{Materials and Methods}

\section{Plant material}

Eight sweetpotato cultivars or breeding lines with yellow fresh, cv. Kokei 14, Tamaotome, Benimasari, Beniharuka, Kyushu 121, Kyushu 138, Kyushu 149 and Kyukei 280, and four cultivars with orange fresh, cv. Benihayato, Sunny-Red, J-Red and Hamakomachi, were cultivated at National Agricultural Research Center for Kyushu Okinawa Region in 2009. The neighboring distances between the rows and the plants were $0.75 \mathrm{~m}$ and $0.35 \mathrm{~m}$, respectively. Compost was applied at $10 \mathrm{t} / \mathrm{ha}$, and chemical fertilizer $(\mathrm{N}: \mathrm{P}: \mathrm{K}$ $=8: 12: 20)$ was applied at $600 \mathrm{~kg} / \mathrm{ha}$. The cultivars were transplanted in an experimental plot in May and harvested in October. Five healthy roots of each cultivar/line were sampled and freeze-dried. Their flesh colors are shown in Table 1 on the basis of the descriptors for the characterization and evaluation of plant genetic resources by Nagamine and Takeda (1999). A breeding line, Kyushu 150, with yellow flesh was also cultivated in the same way in another experimental plot and used for the isolation of carotenoids.

\section{Extraction of carotenoids}

Three $\mathrm{mL}$ of acetone was added to one gram of freezedried powder (equivalent to about $2.5 \mathrm{~g}$ of fresh weight) of each cultivar or line in a centrifuge tube and mixed using a vortex mixer. Five freeze-dried samples of each cultivar/line were used. The mixtures were centrifuged at $1,500 \times \mathrm{g}$ for $10 \mathrm{~min}$. One $\mathrm{mL}$ aliquot of the upper layer of the supernatant was taken, and $3 \mathrm{~mL}$ of acetone was added to the rest. After reextracting, $3 \mathrm{~mL}$ of the upper layer was taken, and the combined extract was used for the measurement of the total carotenoid content by absorption spectrophotometry. For the carotenoid composition by HPLC, the extract was evaporated to dryness under a stream of nitrogen gas, and the residue was redissolved in one $\mathrm{mL}$ of tetrahydrofuran containing $0.1 \%$ BHT and filtered through a membrane filter (DISMIC13HP, $0.2 \mu \mathrm{m}$, ADVANTEC, Tokyo, Japan).

\section{Carotenoid content and compositions}

The UV-Vis spectra of the extracts were recorded in the wavelength of $360-500 \mathrm{~nm}$ with a spectrophotometer (UV3100 , Shimadzu, Kyoto, Japan). The extracts from orangefleshed cultivars were diluted 10 times. The total carotenoid content was calculated using the extinction coefficient of $E=2500$ at $\lambda \max$ (Schiedt and Liaaen-Jense 1995).

The content of each individual carotenoid was calculated
Table 1. Total carotenoid content (milligrams per 100 grams of dry weight) in sweetpotato with yellow and orange flesh

\begin{tabular}{llccc}
\hline \hline Cultivars & Flesh color $^{a}$ & Mean $^{b}$ & SD $^{c}$ & \\
\hline Beniharuka & Cream & 1.3 & 0.2 & $\mathrm{e}^{d}$ \\
Kokei 14 & Cream & 1.9 & 0.3 & $\mathrm{e}$ \\
Kyushu 138 & Cream & 2.0 & 0.2 & $\mathrm{e}$ \\
Kyukei 280 & Pale yellow & 2.4 & 0.4 & $\mathrm{e}$ \\
Benimasari & Pale yellow & 2.7 & 0.3 & $\mathrm{e}$ \\
Kyushu 149 & Pale yellow & 2.7 & 0.3 & $\mathrm{e}$ \\
Kyushu 121 & Yellow & 3.3 & 0.3 & $\mathrm{e}$ \\
Tamaotome & Yellow & 3.9 & 0.3 & $\mathrm{e}$ \\
\hline J-Red & Orange & 13.5 & 1.0 & $\mathrm{~d}$ \\
Benihayato & Orange & 23.9 & 3.7 & $\mathrm{c}$ \\
Sunny-Red & Orange & 33.5 & 5.3 & $\mathrm{~b}$ \\
Hamakomachi & Orange & 39.9 & 1.9 & $\mathrm{a}$
\end{tabular}

${ }^{a}$ Flesh color was visually determined on the basis of the descriptors for the characterization and evaluation of plant genetic resources in Nagamine and Takeda (1999).

${ }^{b}$ Mean value of five individual tubers.

${ }^{c}$ Standard deviation.

${ }^{d}$ Small letters indicate significant differences based on Tukey's comparison $(P<0.01)$.

from the peak area of the analytical HPLC. The percentages of the individual carotenoids of the 17 identified carotenoids were also calculated. The HPLC system consisted of two pumps (LC-10AT, Shimadzu, Kyoto, Japan), an autoinjector (SIL-10AXL, Shimadzu), a column oven (CTO-10AC, Shimadzu), and a photodiode array detector (SPD-M10AVP UV-vis, Shimadzu). A reversed-phase column was used (Wakopack Navi C30-5, $250 \times 30 \mathrm{~mm}$ i.d., $5 \mu \mathrm{m}$, Wako Chemicals Co., Ltd., Osaka, Japan), coupled to a PEEK precolumn. The mobile phase consisted of acetonitrile/water (90/10) containing $0.05 \%$ triethylamine (solvent A) and acetonitrile/methanol/chloroform $(75: 10: 15)$ containing $0.05 \%$ triethylamine (solvent B) at a flow rate of $0.85 \mathrm{~mL} / \mathrm{min}$ at $35^{\circ} \mathrm{C}$. The elution profiles were as follows: solvent $\mathrm{B}$ conc. $0-100 \%$ linear gradient $(0-20 \mathrm{~min}), 100 \%$ (20-40 min), $100-0 \%$ linear gradient (40-41 $\mathrm{min})$ and $0 \%$ (41-60 min). Under this condition, no saponification step was necessary for carotenoids from sweetpotato. The identification of nine known carotenoids, $\beta$-carotene (peak 17), $\beta$-carotene-5,8epoxide (peak 15), $\beta$-carotene 5,8;5', $8^{\prime}$-diepoxide (peaks 12 and 13 , diastereomer), $\beta$-carotene 5,$8 ; 5^{\prime}, 8^{\prime}$-diepoxide (peak 11 , cis isomer), $\beta$-cryptoxanthin $5^{\prime}, 8^{\prime}$-epoxide (peak 9), $\beta$ cryptoxanthin 5,$8 ; 5^{\prime}, 8^{\prime}$-diepoxide (peak 8 ), ipomoeaxanthin A (peak 3), ipomoeaxanthin $\mathrm{C} 1$ (peak 6) and ipomoeaxanthin C2 (peak 7), was based on UV-Vis, FABMS and ${ }^{1} \mathrm{H}$ NMR spectroscopic data. Other detected peaks $(1,2,4,5,10,14$ and 16) were regarded as unknown carotenoids based on the spectral features. The detection wavelengths of peaks 7, 8, 9, 12,13 and 15 were at $430 \mathrm{~nm}$, and those of peaks 1, 2, 3, 4, $5,6,10,11,14,16$ and 17 were at $450 \mathrm{~nm}$. Quantification of carotenoids was carried out by the external standard of $\beta$ carotene. 


\section{Isolation of carotenoids}

Two kg of the freeze-dried powder of the yellow-fleshed sweetpotato Kyushu 150 was extracted with $4 \mathrm{~L}$ of acetone at room temperature. The extract was dried by rotary evaporation and dissolved in $400 \mathrm{~mL}$ of $5 \% \mathrm{KOH} / \mathrm{MeOH}$ at room temperature for 3 hours. The extract was partitioned using $400 \mathrm{~mL}$ of diethyl ether and $200 \mathrm{~mL}$ of distilled water. The diethyl ether layer was dried by rotary evaporation and redissolved in $100 \mathrm{~mL}$ of acetone. The extract was chromatographed on a preparative HPLC on ODS $(250 \times 30 \mathrm{~mm}$ i.d., $5 \mu \mathrm{m}$, YMC-Pack ODS-AM AM-302; YMC, Kyoto, Japan) with a guard column. The mobile phase consisted of acetonitrile/water (90/10) (solvent A) and ethyl acetate (solvent B) at a flow rate of $8 \mathrm{~mL} / \mathrm{min}$ at $35^{\circ} \mathrm{C}$. The elution profiles were as follows: solvent $\mathrm{B}$ conc. $0-50 \%$ linear gradient $(0$ $20 \mathrm{~min}), 50 \%(20-40 \mathrm{~min}), 50-0 \%$ linear gradient $(40$ $41 \mathrm{~min})$, and $0 \%(41-60 \mathrm{~min})$ with detection at $430 \mathrm{~nm}$. The isolated peaks were chromatographed repeatedly, and, finally, $\beta$-carotene, $\beta$-carotene 5,8;5',8'-diepoxide, $\beta$-carotene 5,$8 ; 5^{\prime}, 8^{\prime}$-diepoxide (cis isomer), $\beta$-cryptoxanthin $5^{\prime}, 8^{\prime}$ epoxide, ipomoeaxanthin $\mathrm{C} 1+\mathrm{C} 2$ and ipomoeaxanthin $\mathrm{A}$ were isolated.

\section{ABTS radical-scavenging activity}

The 2,2'-azino-bis (3-ethylbenzothiazoline-6-sulfonic acid) diammonium salt (ABTS) radical-scavenging activity of the isolated carotenoids was evaluated according to the method by Oki et al. (2006). Eighty-eight microliters of $140 \mathrm{mM}$ potassium peroxodisulfate was added to $5 \mathrm{~mL}$ of a $7 \mathrm{mM}$ ABTS stock solution in water, and the mixture was stored for 16 hours at room temperature in the dark. Before the reaction, the generated ABTS cation radical solution was diluted 16 times with ethanol. The isolated carotenoids were dissolved in acetone/ethanol $(1 / 1 \mathrm{v} / \mathrm{v})$ at a concentration of $0.02 \mathrm{mM}$. Fifty microliters of the sample was transferred to a 96-well microplate, and $50 \mu \mathrm{L}$ of ethanol and $100 \mu \mathrm{L}$ of an ABTS working solution were added. After a 30-min reaction, the absorbency at $630 \mathrm{~nm}$ was measured. The data were expressed as $\mathrm{IC}_{50}(\mu \mathrm{M})$, the carotenoid concentration for $50 \%$ scavenging of the ABTS cation radical.

\section{Results}

\section{Total carotenoid content}

The total carotenoid contents in 8 cultivars or breeding lines with yellow flesh were evaluated and compared to those of 4 cultivars with orange flesh by absorption spectrophotometry (Table 1). The content ranged from $1.3 \mathrm{mg} /$ $100 \mathrm{~g}$ dry weight to $3.9 \mathrm{mg} / 100 \mathrm{~g}$ dry weight in yellowfleshed cultivars/lines and from $13.5 \mathrm{mg} / 100 \mathrm{~g}$ dry weight to $39.9 \mathrm{mg} / 100 \mathrm{~g}$ dry weight in orange-fleshed cultivars. The contents in the cultivars with yellow flesh were significantly lower than those in the cultivars with orange flesh. A significant difference in the carotenoid content among cultivars with orange flesh was also observed.

\section{Carotenoid composition}

Individual carotenoids in yellow flesh were analyzed by HPLC and compared to those in orange flesh. Many carotenoids, including nine known carotenoids, were separated (Fig. 1). The total amounts of individual carotenoids, the sum of nine known carotenoids and eight unknown carotenoids, are shown in Table 2 . The amount highly correlated with the total carotenoid content analyzed spectrophotometrically (Fig. 2). The difference in the total carotenoid content obtained by HPLC and that by spectrophotometric analysis was not significant (data not shown), although the content by HPLC was slightly higher than that by spectrophotometrical analysis.

The main carotenoids were $\beta$-carotene 5,$8 ; 5^{\prime}, 8^{\prime}$ diepoxide and $\beta$-cryptoxanthin 5,8 -epoxide in yellowfleshed cultivars/lines, while $\beta$-carotene was dominant in orange-fleshed cultivars. The $\beta$-carotene 5,$8 ; 5^{\prime}, 8^{\prime}$-diepoxide (peaks 11, 12 and 13) content ranged from ca. 32\% to ca. $51 \%$, and the $\beta$-cryptoxanthin 5,8-epoxide (peak 9) content ranged from ca. $11 \%$ to ca. $30 \%$ in yellow-fleshed cultivars/ lines (Table 2). On the other hand, the $\beta$-carotene (peak 17) content in orange-fleshed cultivars ranged from ca. $80 \%$ to ca. $92 \%$ (Table 2 ). These results indicate that the carotenoid component in the yellow- and orange-fleshed cultivars was almost identical but the content of each carotenoid was completely different between the yellow- and orange-fleshed cultivars.

\section{ABTS radical-scavenging activity of carotenoids}

The carotenoids were isolated from yellow-fleshed tubers, and their ABTS anti-oxidative activities were analyzed (Table 3). The $\mathrm{IC}_{50}$ values ranged from $6.6 \mu \mathrm{M}$ ( $\beta$-carotene) to $17.8 \mu \mathrm{M}$ ( $\beta$-cryptoxanthin-5,8-epoxide). The antioxidative activity of ipomoeaxanthin A was approximately the same as that of $\beta$-carotene, and those of the main carotenoids, $\beta$-carotene 5,$8 ; 5^{\prime}, 8^{\prime}$-diepoxide and $\beta$-cryptoxanthin 5,8 -epoxide, were lower than that of $\beta$-carotene.

\section{Discussion}

The total carotenoid contents of the cultivars with yellow or orange flesh were evaluated by absorption spectrophotometry (Table 1) and HPLC (Table 2). The content by both methods showed high correlations (Fig. 2), and there was no significant difference between both methods. This result indicates that the total carotenoid content can be easily evaluated spectrophotometrically. The evaluation of yellow flesh is sometimes uncertain because the results are based on visual determination. The results of our studies indicate that flesh color, from white to yellow, could be accurately determined by the total carotenoid content. For example, flesh color with a total carotenoid content of under $1.0 \mathrm{mg} / 100 \mathrm{~g}$ DW is white or pale cream, from $1.0-2.0 \mathrm{mg} / 100 \mathrm{~g} \mathrm{DW}$ is cream, from $2.0-3.0 \mathrm{mg} / 100 \mathrm{~g} \mathrm{DW}$ is pale yellow and over $3.0 \mathrm{mg} / 100 \mathrm{~g} \mathrm{DW}$ is yellow. The color values of flesh, in particular, the $a^{*}$ value, were correlated with the content of 
Table 2. Contents (micrograms per 100 grams of dry weight ) and proportions of individual carotenoids (\%) in cultivars/lines with yellow or orange flesh

\begin{tabular}{|c|c|c|c|c|c|c|c|c|c|c|c|c|c|c|c|c|c|c|c|}
\hline & $\begin{array}{l}\text { Peak } \\
\text { No. }{ }^{a}\end{array}$ & 1 & 2 & 3 & 4 & 5 & 6 & 7 & 8 & 9 & 10 & 11 & 12 & 13 & 14 & 15 & 16 & 17 & total \\
\hline \multirow[t]{3}{*}{ Beniharuka } & $\operatorname{Mean}^{b}$ & 25.5 & 8.5 & 36.3 & 6.6 & 74.7 & 60.6 & 28.6 & 14.0 & 205.8 & 73.0 & 217.9 & 102.7 & 132.9 & 23.8 & 92.1 & n.d. & 28.2 & 1,131 \\
\hline & $\mathrm{SD}^{c}$ & & 1.0 & 2.8 & 1.2 & 18.1 & 11.4 & 4.8 & 4.1 & 15.0 & 17.6 & 52.4 & 20.0 & 28.8 & 5.3 & & - & 7.6 & 176 \\
\hline & $\%$ & 2.3 & 0.8 & 3.3 & 0.6 & 6.5 & 5.3 & 2.5 & 1.2 & 18.5 & 6.4 & 19.0 & 9.0 & 11.7 & 2.1 & 8.2 & - & 2.5 & 100 \\
\hline \multirow[t]{3}{*}{ Kokei 14} & Mean & 40.6 & 14.0 & 30.4 & 14.6 & 113.9 & 54.9 & 30.9 & 19.6 & 199.3 & 156.9 & 344.7 & 162.9 & 212.2 & 49.4 & 69.1 & n.d. & 120.8 & 1,634 \\
\hline & SD & 10.7 & 3.3 & 3.8 & 4.4 & 33.0 & 8.9 & 4.8 & 9.2 & 14.5 & 68.6 & 128.9 & 16.1 & 31.3 & 14.7 & 13.4 & - & 55.1 & 253 \\
\hline & $\%$ & 2.5 & 0.9 & 1.9 & 0.9 & 6.9 & 3.4 & 1.9 & 1.2 & 12.4 & 9.4 & 20.8 & 10.1 & 13.2 & 3.0 & 4.3 & - & 7.4 & 100 \\
\hline \multirow[t]{3}{*}{ Kyushu 138} & Mean & 17.1 & 4.3 & 27.7 & 9.4 & 82.6 & 112.3 & 38.4 & 17.4 & 244.7 & 62.8 & 296.1 & 199.7 & 404.7 & 33.5 & 140.5 & n.d. & 51.2 & 1,742 \\
\hline & SD & 6.6 & 4.0 & 3.2 & 1.7 & 15.8 & 8.6 & 2.0 & 2.1 & 19.8 & 9.1 & 69.9 & 27.7 & 49.0 & 2.4 & 9.5 & - & 28.2 & 179 \\
\hline & $\%$ & 1.0 & 0.2 & 1 & 0.5 & 4.7 & 6.5 & 2.2 & 1.0 & 14.1 & 3.6 & 16.8 & 11.4 & 23 & 1.9 & .1 & - & .0 & 100 \\
\hline \multirow[t]{3}{*}{ Kyukei 280} & Mean & 39.4 & 17.2 & 103.0 & 9.9 & 112.0 & 109.8 & 37.5 & 27.0 & 754.8 & 52.4 & 226.4 & 158.0 & 436.7 & 50.5 & 188.5 & n.d. & 192.3 & 2,516 \\
\hline & SD & 12.5 & 5.9 & 13.6 & 2.7 & 28.0 & 16.3 & 5.5 & 1.9 & 97.9 & 18.7 & 79.8 & 25.6 & 76.8 & 6.9 & 40.4 & - & 79.1 & 329 \\
\hline & $\%$ & 1.5 & 0.7 & 4.1 & 0.4 & 4.4 & 4.4 & 1.5 & 1.1 & 30.0 & 2.0 & 8.8 & 6.3 & 17.3 & 2.0 & 7.4 & - & 8.1 & 100 \\
\hline \multirow[t]{3}{*}{ Benimasari } & Mean & 50.3 & 21.2 & 61.9 & 7.7 & 113.0 & 143.2 & 94.0 & 37.8 & 388.1 & 57.3 & 231.3 & 222.4 & 404.0 & 36.7 & 91.4 & n.d. & 126.2 & 2,087 \\
\hline & SD & 12.5 & 2.1 & 4 & 1.2 & 26.2 & 12.0 & 55.3 & 4.1 & 32.7 & 15.9 & 57.8 & 28.8 & 52.1 & 5.4 & 17.3 & - & 24.7 & 219 \\
\hline & $\%$ & 2 & 1.0 & 3 & 0.4 & 5.4 & 6.9 & 4.4 & 1.8 & 18.7 & 2.7 & 11.0 & 10.6 & 19.3 & 1.8 & 4.4 & - & 6.1 & 00 \\
\hline \multirow[t]{3}{*}{ Kyushyu 149} & Mean & 69.7 & 20.2 & 44.8 & 43.8 & 156.6 & 80.6 & 32.1 & 16.7 & 284.9 & 241.0 & 584.2 & 184.7 & 387.8 & 116.0 & 231.9 & n.d. & 53.1 & 2,548 \\
\hline & SD & 16.2 & 4.1 & 3.8 & 12.9 & 21.4 & 8.6 & 3.7 & 1.1 & 29.9 & 44.1 & 84.7 & 20.0 & 42.6 & 31.5 & 77.9 & - & 18.0 & 301 \\
\hline & $\%$ & 2.8 & 0.8 & 1.8 & 1.7 & 6.2 & 3.2 & 1.3 & 0.7 & 11.3 & 9.4 & 22.9 & 7.3 & 15.3 & 4.5 & 9.0 & - & 2.1 & 100 \\
\hline \multirow[t]{3}{*}{ Kyushu 121} & Mean & 41.2 & 9.7 & 46.8 & 27.8 & 154.7 & 149.7 & 48.9 & 33.3 & 525.0 & 122.3 & 634.3 & 323.4 & 744.1 & 68.1 & 338.9 & n.d. & 84.7 & 3,353 \\
\hline & SD & 9.3 & 2.0 & 5.1 & 5.2 & 23.8 & 16.1 & 6.6 & 5.0 & 43.5 & 23.5 & 128.4 & 67.7 & 141.4 & 35.3 & 74.2 & - & 7.1 & 363 \\
\hline & $\%$ & 1.3 & 0.3 & 1.4 & 0.8 & 4.6 & 4.5 & 1.5 & 1.0 & 15.8 & 3.6 & 18.8 & 9.6 & 22.0 & 2.1 & 10.2 & - & 2.6 & 100 \\
\hline \multirow[t]{3}{*}{ Tamaotome } & Mean & 71.0 & 16.1 & 54.9 & 13.6 & 236.2 & 174.0 & 77.2 & 26.5 & 422.1 & 287.9 & 835.4 & 365.1 & 694.5 & 131.3 & 323.1 & n.d. & 179.7 & 3,908 \\
\hline & SD & 11.3 & 2.8 & 5.9 & 2.9 & 32.0 & 15.3 & 6.7 & 3.4 & 50.2 & 79.2 & 173.8 & 35.5 & 67.8 & 29.3 & 42.7 & - & 4.8 & 477 \\
\hline & $\%$ & 1.8 & 0.4 & 1.4 & 0.3 & 6.0 & 4.5 & 2.0 & 0.7 & 10.8 & 7.3 & 21.2 & 9.4 & 17.8 & 3.3 & 8.3 & - & 4.6 & 100 \\
\hline \multirow[t]{3}{*}{ J-Red } & Mear & 73.3 & 71.0 & 61.3 & 89.1 & 75.5 & 27.9 & 15.4 & 6.1 & 173.2 & 491.9 & 238.3 & 66.3 & 66.1 & 1277.5 & 197.1 & 101.5 & 11,760 & 14,791 \\
\hline & SI & 23.6 & 17.9 & 25.6 & 19.4 & 9.6 & 2. & 1. & 3.5 & 10.5 & 23.6 & 23.9 & & 7.2 & 45.5 & 18.2 & 9.8 & 407.7 & 470 \\
\hline & $\%$ & 0.5 & 0.5 & 0.4 & 0.6 & 0.5 & 0.2 & 0.1 & 0.0 & 1.2 & 3.3 & 1.6 & 0.4 & 0.4 & 8.6 & 1.3 & 0.7 & 79.5 & 100 \\
\hline \multirow[t]{3}{*}{ Benihayato } & Mean & 211.7 & 146.1 & 12.1 & 185.9 & 7.6 & n.d. & n.d. & n.d. & 52.5 & 68.6 & 59.9 & 8.5 & 24.7 & 495.8 & 185.1 & 278.6 & 19,125 & 20,863 \\
\hline & SD & 35.9 & 21.4 & 2.1 & 36.7 & 7.2 & - & - & - & 30.8 & 48.4 & 45.6 & 6.9 & 10.7 & 173.1 & 41.0 & 35.2 & 1864.5 & 2,118 \\
\hline & $\%$ & 1.0 & 0.7 & 0.1 & 0.9 & 0.0 & - & - & - & 0.2 & 0.3 & 0.3 & 0.0 & 0.1 & 2.3 & 0.9 & 1.3 & 91.7 & 100 \\
\hline \multirow[t]{3}{*}{ Sunny-Red } & Mean & 103.9 & 47.7 & 69.2 & 161.9 & 185.6 & 71.9 & 57.7 & 23.2 & 338.5 & 969.2 & 963.3 & 243.9 & 365.9 & 2671.6 & 762.9 & 296.5 & 32,276 & 39,609 \\
\hline & SD & 48.6 & 4.5 & 9.5 & 20.9 & 22.6 & 10.8 & 11.7 & 5.1 & 35.2 & 76.6 & 137.6 & 22.8 & 197.8 & 225.2 & 69.0 & 41.7 & 5938.1 & 5,977 \\
\hline & $\%$ & 0.3 & 0.1 & 0.2 & 0.4 & 0.5 & 0.2 & 0.1 & 0.1 & 0.9 & 2.5 & 2.5 & 0.6 & 1.0 & 6.8 & 1.9 & 0.8 & 81.2 & 100 \\
\hline \multirow{3}{*}{$\begin{array}{l}\text { Hama- } \\
\text { komachi }\end{array}$} & Mean & 61.6 & 37.0 & 72.3 & 161.2 & 99.3 & 41.7 & 47.2 & 7.7 & 265.7 & 701.6 & 471.5 & 95.9 & 175.3 & 3062.3 & 516.9 & 275.8 & 40,094 & 46,187 \\
\hline & $\mathrm{SD}$ & 13.1 & 6.5 & 4.8 & 30.7 & 22.4 & 8.9 & 6.5 & 7.0 & 24.3 & 114.6 & 86.2 & 16.1 & 23.6 & 274.5 & 67.9 & 28.5 & 1679.4 & 2,198 \\
\hline & $\%$ & 0.1 & 0.1 & 0.2 & 0.3 & 0.2 & 0.1 & 0.1 & 0.0 & 0.6 & 1.5 & 1.0 & 0.2 & 0.4 & 6.6 & 1.1 & 0.6 & 86.8 & 100 \\
\hline
\end{tabular}

${ }^{a}$ Peak 1: unknown, 2: unknown, 3: ipomoeaxanthin A, 4: unknown, 5: unknown, 6: ipomoeaxanthin $\mathrm{C} 1$, 7: ipomoeaxanthin $\mathrm{C} 2,8$ : $\beta$-crypthoxanthin 5,8;5', $8^{\prime}$-diepoxide, 9: $\beta$-crypthoxanthin 5,8-epoxide, 10: unknown, 11 : $\beta$-carotene 5,8;5', $8^{\prime}$-diepoxide (cis-isomer), $12,13: \beta$-carotene 5,8;5', $8^{\prime}$ diepoxide (diastereomer), 14: unknown, 15: $\beta$-carotene 5,8-epoxide, 16: unknown, 17: $\beta$-carotene.

${ }^{b}$ The values represent the mean of five individual tubers.

${ }^{c}$ Standard deviation.

$\beta$-carotene in orange-fleshed sweetpotato cultivars/lines (Takahata et al. 1993). This method might also be useful for the evaluation of yellow flesh as a rapid method in breeding.

The carotenoids in yellow sweetpotatoes were separated by HPLC and compared to those of orange-fleshed sweetpotatoes. Seventeen carotenoids, including nine known ones, were detected (Fig. 1). A saponification step was not necessary for carotenoid separation from sweetpotato under the adopted HPLC condition, although auroxanthin and neochrome were not detected but were later recognized after saponification. The carotenoid component in yellow and orange flesh was almost identical, but the content of each differed distinctly in the yellow- and orange-fleshed tubers (Fig. 1 and Table 2). The proportion of carotenoids with the epoxy and hydroxyl groups was high in the yellow-fleshed cultivars, while $\beta$-carotene was dominant in the orangefleshed ones. These results are consistent with previous reports that $\beta$-carotene and $\beta$-carotene epoxides and $\beta$ cryptoxanthin epoxides are the principal pigments in orangefleshed cultivars and a yellow-fleshed cultivar cv. Benimasari, respectively (Kimura et al. 2007, Maoka et al. $2007)$. In the carotenoid pathway, $\beta$-cryptoxanthin is synthesized by adding a hydroxyl group to a $\beta$ ring of $\beta$-carotene (Burns et al. 2003). The balance of the synthesis of $\beta$ carotene and metabolization to the $\beta$-carotene epoxide or $\beta$ crypthoxanthin epoxide could be a determinant of the flesh color of the sweetpotato tuber. In other words, a higher expression of $\beta$-carotene results in orange flesh, and higher 

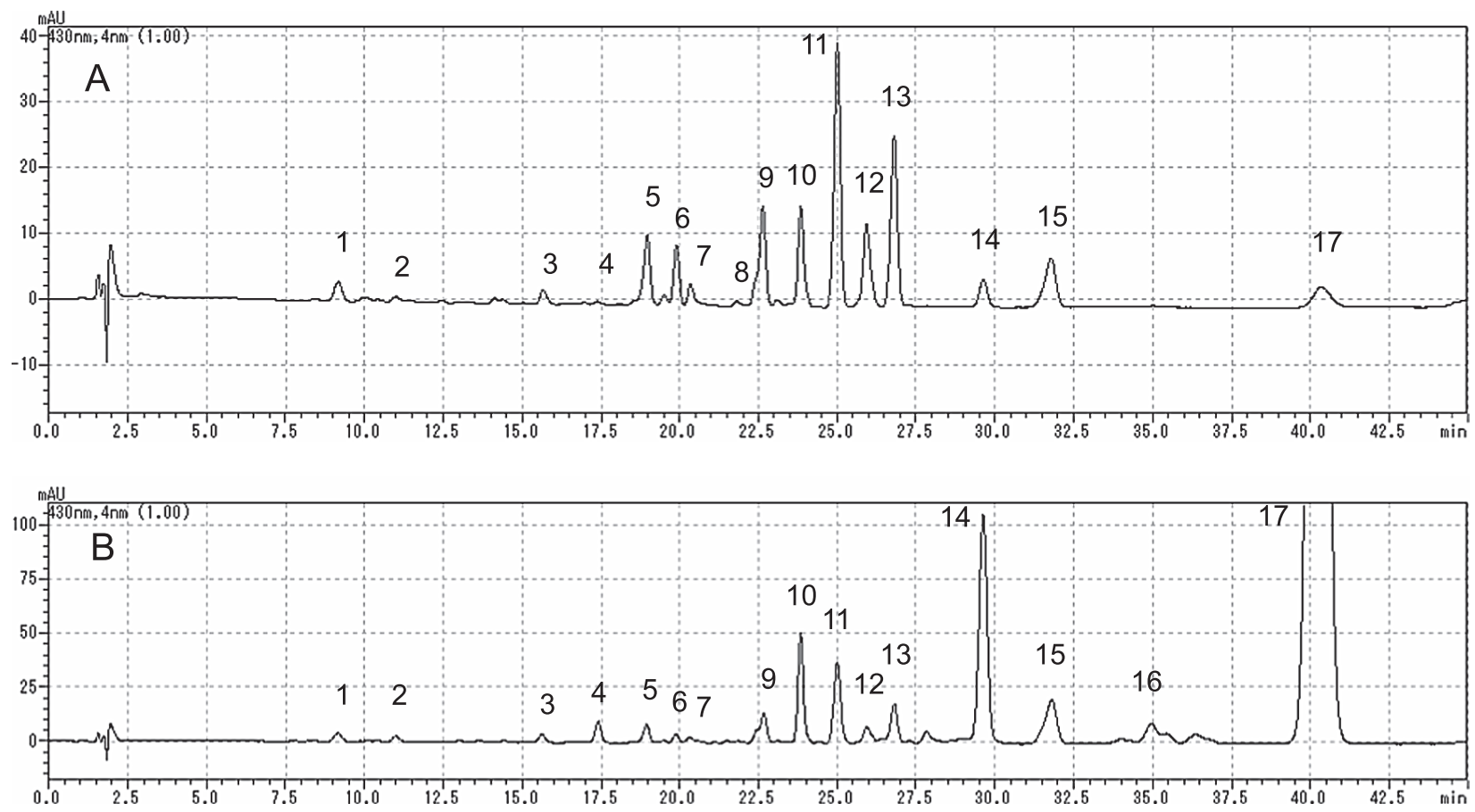

Fig. 1. HPLC chromatograms of carotenoids from (A) yellow-fleshed cv. Tamaotome and (B) orange-fleshed cv. Sunny-Red. Peak identifications 1: unknown, 2: unknown, 3: ipomoeaxanthin A, 4: unknown, 5: unknown, 6: ipomoeaxanthin $\mathrm{C} 1$, 7: ipomoeaxanthin $\mathrm{C} 2$, 8: $\beta$-crypthoxan-

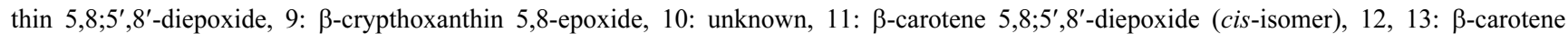
5,8;5', $8^{\prime}$-diepoxide (diastereomer), 14: unknown, 15: $\beta$-carotene 5,8-epoxide, 16 : unknown, 17 : $\beta$-carotene.
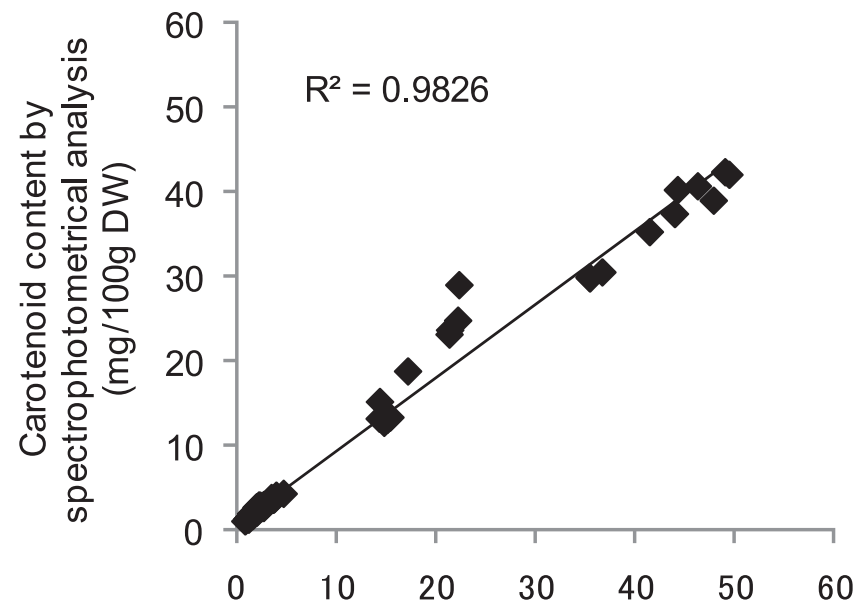

Carotenoid content by HPLC
$(\mathrm{mg} / 100 \mathrm{~g}$ DW)

Fig. 2. Correlation between the carotenoid content (milligrams per 100 grams of dry weight) by HPLC and by spectrophotometrical analysis.

accumulation of $\beta$-carotene epoxide and $\beta$-crypthoxanthin epoxide leads to yellow flesh in sweetpotato tubers.

Carotenoids isolated from yellow sweetpotato tubers showed an antioxidative effect according to their ABTS radical-scavenging activity. These carotenoids probably act as a radical scavenger, similarly to other carotenoids already reported. Previous reports indicated that the most predomi-
Table 3. ABTS radical-scavenging activity of carotenoids isolated from yellow-fleshed sweetpotato

\begin{tabular}{llr}
\hline \hline Peak No. & \multicolumn{1}{c}{ Carotenoids } & $\mathrm{IC}_{50}(\mu \mathrm{M})$ \\
\hline 3 & Ipomoeaxanthin A & 6.7 \\
6,7 & Ipomoeaxanthin C1 + C2 & 8.6 \\
9 & $\beta$-cryptoxanthin 5,8-epoxide & 17.8 \\
11 & $\beta$-carotene 5,$8 ; 5^{\prime}, 8^{\prime}$-diepoxide $($ cis $)$ & 9.8 \\
12,13 & $\beta$-carotene 5,$8 ; 5^{\prime}, 8^{\prime}$-diepoxide & 10.2 \\
17 & $\beta$-carotene & 6.6 \\
\hline
\end{tabular}

nant contributor to the radical-scavenging activity in the lipophilic fraction in some orange-fleshed cultivars would be $\beta$-carotene (Oki et al. 2006). On the other hand, a large amount of $p$-coumaric acid esters, rather than yellow pigments, contributed significantly to the radical-scavenging activity in the lipophilic fraction of yellow-fleshed sweetpotato (Ishiguro et al. 2008). A reason for the lack of correlation between the radical scavenging activity and the carotenoid content in yellow-fleshed sweetpotato could be that the carotenoid content is lower than that in orangefleshed sweetpotato. The lower antioxidative activities of the main carotenoids, $\beta$-carotene- 5,$8 ; 5^{\prime}, 8^{\prime}$-diepoxide and $\beta$ cryptoxanthin-5,8-epoxide, in yellow-fleshed sweetpotato would be another reason for the lower contribution of the carotenoids to the antioxidative activities in yellow-fleshed sweetpotato. Elevation of the carotenoid content in yellowfleshed cultivars might lead to a higher contribution of 
carotenoids to the antioxidative activity in the lipophilic fraction of sweetpotato. One objective of sweetpotato breeders is to develop a variety with deep-yellow flesh. Deep yellow is an attractive color in processed foods, and carotenoids may contribute to the prevention of some diseases due to their antioxidative effects.

In conclusion, the results of this study showed that there were some carotenoids with antioxidative activity in yellowfleshed sweetpotato tubers, their carotenoid components were almost identical to that of orange-fleshed tubers, and the content and proportion of each carotenoid were the determinant of flesh color from yellow to orange. $\beta$-carotene epoxides and $\beta$-crypthoxanthin epoxides, which are abundant in the yellow-fleshed cultivars, are noteworthy components for the breeding selection of sweetpotato with deep yellow flesh.

\section{Literature Cited}

Burns,J., P.D.Fraser and P.M.Bramley (2003) Identification and quantification of carotenoids, tocopherols and chlorophylls in commonly consumed fruits and vegetables. Phytochemistry 62: 939-947.

Ishiguro, K., O. Yamakawa, T.Kumagai, M.Yoshinaga, M. Hidaka, Y.Kai, K.Komaki and H.Kukimura (2004a) Tamaotome; new sweetpotato cultivar for dried products after steaming. Bull. Natl. Agric. Res. Cent. Kyushu Okinawa Region 43: 27-58.

Ishiguro, K., O.Yamakawa, T.Kumagai, M.Yoshinaga, Y.Kai and M.Hidaka (2004b) Benimasari; new sweetpotato cultivar for table use. Bull. Natl. Agric. Res. Cent. Kyushu Okinawa Region 43: 5985.

Ishiguro, K., M.Yoshimoto, M.Suzuki and S. Yahara (2008) Antioxidative activity in the lipophilic fraction of sweet potato tubers. Acta Hort. 768: 571-577.

Kai,Y., K.Katayama, T.Sakai and M.Yoshinaga (2004) Ayakomachi: new sweetpotato cultivar for cooking material and table use. Sweetpotato Research Front 17: 4.

Kai, Y., K.Katayama, T.Sakai and M.Yoshinaga (2010) Beniharuka: a new sweetpotato cultivar for table use. Sweetpotato Research Front 23: 2.

Kashimura,E., K.Yoneyama, R.Suga and E.Nakagawa (2005) On the semi new recommended cultivar of sweet potato (Ipomoea batatas) "Murasakimasari" in Ibaraki prefecture. Bull. Agric. Res. Inst. Ibaraki Agric. Cent. 8: 35-41.

Kimura,M., C.N.Kobori, D.B.Rodriguez-Amaya and P.Nestel (2007) Screening and HPLC methods for carotenoids in sweetpotato, cassava and maize for plant breeding trials. Food Chem. 100:
1734-1746.

Komaki,K. and O.Yamakawa (2006) R\&D collaboration with industry-The Japanese sweetpotato story. Acta Hort. 703: 23-29.

Maoka,T., N.Akimoto, K.Ishiguro, M. Yoshinaga and M. Yoshimoto (2007) Carotenoids with a 5,6-dihydro-5,6-dihydroxy-beta-end group, from yellow sweet potato "Benimasari", Ipomoea batatas LAM. Phytochemistry 68: 1740-1745.

Mayne,S.T. (1996) Beta-carotene, carotenoids, and disease prevention in humans. Faseb Journal 10: 690-701.

Nagamine, T. and H.Takeda (1999) Sweetpotato. In: Nagamine, T. and H.Takeda (eds.) The Descriptors for Characterization and Evaluation in Plant Genetic Resources, Volume 1, National Institute of Agrobiological Resources, The Ministry of Agriculture, Forestry and Fisheries of Japan, pp. 43-46.

Oki,T., S.Nagai, M.Yoshinaga, Y.Nishiba and I.Suda (2006) Contribution of beta-carotene to radical scavenging capacity varies among orange-fleshed sweet potato cultivars. Food Sci. Technol. Res. 12: 156-160.

Sakai, T., T.Kumagai, Y.Kai, K.Ishiguro, O.Yamakawa, K.Katayama, Y.Nakazawa and M.Yoshinaga (2010) "Akemurasaki": A new sweetpotato cultivar. Bull. Natl. Agric. Res. Cent. Kyushu Okinawa Region 53: 1-24.

Schiedt, K. and S.Liaaen-Jensen (1995) Isolation and analysis. In: Britton,G., S.Liaaen-Jensen and H.Pfander (eds.) Carotenoids, vol. 1B, Birkhäuser Verlag, Basel, pp. 81-108.

Shih,C.K., J.H.Chang, S.H.Yang, T.W.Chou and H.H.Cheng (2008) Beta-carotene and canthaxanthin alter the pro-oxidation and antioxidation balance in rats fed a high-cholesterol and high-fat diet. British J. Nutrition 99: 59-66.

Takahata,Y., T.Noda and T.Nagata (1993) HPLC determination of $\beta$ carotene content of sweet potato cultivars and its relationship with color values. Jpn. J. Breed. 43: 421-427.

Tamiya,S., M.Nakatani, K.Komaki, K.Katayama and T.Kuranouchi (2003) New sweet potato cultivar "Purple Sweet Lord". Bull. Natl. Inst. Crop Sci. 4: 29-43.

Yamakawa,O. (1998) Development of sweetpotato cultivars for new processing use in Japan. Trop. Agric. 75: 284-287.

Yamakawa, O., M.Yoshinaga, T.Kumagai, M.Hidaka, K. Komaki, H.Kukimura and K. Ishiguro (1997) "J-Red": a new sweetpotato cultivar. Bull. Natl. Agric. Res. Cent. Kyushu Okinawa Region 33: 49-72.

Yamakawa, O., T.Kumagai, M. Yoshinaga, K. Ishiguro, M. Hidaka, K.Komaki and H.Kukimura (1999) "Sunny-Red": a new sweetpotato (Ipomoea batatas) cultivar for powder. Bull. Natl. Agric. Res. Cent. Kyushu Okinawa Region 35: 19-40.

Yoshinaga,M., Y.Kai, K.Katayama and T.Sakai (2006) New varieties for dried sweetpotato products Hamakomachi and Kyushu No. 137. Sweetpotato Research Front 20: 3. 